\title{
Development of nighttime bladder control from 4 - 9 years: association with dimensions of parent rated child maturational level, child temperament and maternal psychopathology.
}

\section{Carol Joinson PhD*}

Department of Community Based Medicine, University of Bristol, UK Jon Heron PhD

Department of Social Medicine, University of Bristol, UK

\section{Richard Butler PhD}

C.Psychol, Clinical Psychology Department, Child \& Adolescent Mental Health Services, East Leeds Primary Care Trust

Tim Croudace PhD

Department of Psychiatry, University of Cambridge, UK

${ }^{*}$ Corresponding author

Department of Community Based Medicine

University of Bristol

Cotham House

Cotham Hill

Bristol BS6 6JL

Email: Carol.Joinson@bristol.ac.uk

Phone: 01179546693

Fax: 01179546672

\section{Keywords}

Bedwetting; nocturnal enuresis; latent class analysis; developmental typology; prospective study; child development; ALSPAC. 


\section{Abstract}

\section{Background}

This study investigates variability in acquisition of nighttime bladder control in a large, general population sample of children by defining a developmental typology through latent class analysis. We also examined the association of bedwetting classes with contributing factors in early childhood including maturational level, temperament and exposure to maternal psychopathology.

\section{Methods}

We used data from over 10,000 children from age 4-9 years from a UK population sample (Avon Longitudinal Study of Parents and Children). Mothers completed questionnaires asking about their child's bedwetting (on five occasions during the assessment period), maturational level (at 18 months), temperament (24 months), and maternal depressive / anxious psychopathology (21 months). We derived longitudinal phenotypes capturing population heterogeneity in nighttime bladder control using latent class analysis. Associations with the contributing factors were investigated using multinomial logistic regression.

\section{Results}

We identified five groups of children with different patterns of development of nighttime bladder control: 1) normative $(69.9 \%$ of 10,818 sample); (2) delayed $(8.4 \%)$; (3) severely delayed $(9.3 \%)$; (4) persistent $(8.6 \%)$, and (5) relapse (3.8\%). Results indicated that developmental delay, difficult temperament traits and exposure to maternal depressive/anxious symptoms were associated with an increase in the odds of children experiencing problems either attaining nighttime bladder control or with relapse in bedwetting after a period of initial dryness.

\section{Conclusions}

Development of nighttime bladder control and onset of bedwetting problems are captured by this developmental typology approach, enabling factors that affect risk of bedwetting to be determined and targeted. Further investigation is required into contributing factors relating to individuals and their environments that are associated with difficulties attaining or maintaining nighttime continence, including neurobiological and genetic factors.

\section{Introduction}

The attainment of nighttime bladder control is an important milestone in child development. Epidemiological evidence shows that the prevalence of bedwetting decreases with age (Byrd, Weitzman, Lanphear \& Auinger, 1996), with most children remaining dry throughout the night by around 4 to 6 years (Blomfield \& Douglas, 1956; Oppel, Harper \& Rider, 1968; Fergusson, Horwood \& Shannon, 1986). However, it is not uncommon for bedwetting to persist after this age into the early years of schooling, and sometimes beyond. For example, in the UK ALSPAC cohort, $15.5 \%$ of children aged 7.5 years were reported to experience some level of bedwetting, most of whom wet 'less than once a week', while only a small proportion $(2.6 \%)$ wet twice or more in any one week - the frequency required for a DSM-IV diagnosis of nocturnal enuresis (Butler, Golding and Northstone, 2005). Existing data indicate that there is considerable variability between children in their pathways to nighttime continence (Croudace, Jarvelin, Wadsworth \& Jones, 2003; Fergusson, Horwood, Shannon, 1986). Such population heterogeneity in both school children and clinical (help-seeking) samples, suggests that different mechanisms and contributing factors for problems in achieving and maintaining bladder control may be operating. For some children continence may be achieved relatively easily after only a few mishaps; others achieve dry nights after a prolonged period of intermittent success and failure, and some may experience a relapse in bedwetting after previously being dry. Behind these patterns may lie clues to aetiology, neurobiological mechanisms, and possible interplay between genetic and environmental factors. 
In order to understand the reasons for such wide variations in the time course for development of nighttime bladder control, it has proven useful to identify groups of children who show similar patterns in development of continence, or onset of bedwetting problems. This can be done in a variety of ways, including using simple methods such as cluster analysis to define a typology, based on characteristic features. However, in recent years more powerful new methodologies for statistical modelling of longitudinal data have been developed that are particularly suited to such research e.g. model-based clustering methods. These methods are referred to as group based trajectory models (Muthén \& Muthén, 1998-2006; Nagin \& Tremblay, 2005) or latent class (growth) analyses when applied to longitudinal data. For example, Croudace and colleagues (Croudace et al. 2003) studied population heterogeneity in trajectories to nighttime bladder control in the 1946 British birth cohort (the Medical Research Council National Survey of Health and Development- NSHD). Latent class and group-based trajectory modelling techniques were applied to a simple binary recoding of bedwetting reports from parents on six occasions between the ages 4 and 15 years. Models with up to five longitudinal profiles were summarised graphically and a five-class solution offered as longitudinal empirical phenotypes that provide an alternative view to traditional, cross-sectional diagnoses e.g. based on DSM. Clinical diagnoses are often not available in general population samples or birth cohorts. The latent classes described the changing patterns of nighttime bladder control during the period from 4 to 15 years defined in terms of probability of bedwetting in the past month. The most common group in the general population sample was described as having normal development of nighttime bladder control (prevalence $=84.0 \%$ ). This is to be expected since the data collection on bedwetting did not start until age four, censoring the trajectories to continence of the majority of the children. The second most common group exhibited delayed acquisition of nighttime bladder control and were described as "transient" (8.7\%). A small group exhibited "persistent" bedwetting (1.8\%) and a slightly larger group "chronic" bedwetting (2.6\%). The remaining group profile was a latent class for secondary (relapse) or "onset" enuresis i.e. bedwetting that re-emerges anew after a period of initial continence $(2.9 \%)$.

An important limitation of the study by Croudace et al. (2003) was that they did not examine contributing factors for bedwetting, apart from those relating to continence behaviour. Covariates were limited to daytime wetting, bowel control, and extent or duration of toilet training. Also, no other study has been able to attempt a replication of this novel typological perspective. Ideally independent data would be available to examine the robustness of these longitudinal profiles. Additionally, it is important to extend knowledge about contributing factors relating to individuals and their environments that might delay continence milestone attainment or trigger relapses. A previous study in the ALSPAC cohort (Joinson et al. 2008) found an association between previously established developmental trajectories of daytime bladder and bowel control (Heron, Joinson, Croudace \& von Gontard, 2008) and contributing factors in early childhood including developmental delay, difficult temperament and exposure to maternal psychopathology. However, the association of these contributing factors with such a typological perspective on nighttime bladder control is yet to be examined. We believe it is important to examine whether these factors are also associated with the development of nighttime bladder control because this could increase understanding of potential similarities or differences in the aetiology of daytime and nighttime wetting. Also, a typological approach would allow us to examine whether different pathways to nighttime bladder control are differentially associated with these factors.

Risk factors for bedwetting are widely believed to be multi-factorial and to involve a complex interrelationship of genetic, biological, neurological, and psychological factors. In some children, bedwetting appears to be neurodevelopmental, and associated with a fundamental deficit in brain maturation e.g. of neuronal pathways controlling micturition (Barbour, Boyd, Borland, Miller \& Oppel, 1963; Jarvelin, 1989). It is believed that this neurological deficit is linked not only to bedwetting, but also to the increased likelihood of delays in language and motor skill development that have been reported in children who suffer from bedwetting (Essen \& Peckham, 1976; Fergusson et al. 1986; Jarvelin, 1989; Jarvelin et al. 1991; Kawauchi et al. 2001; Touchette et al. 2005; von Gontard, Freitag, Seifen, Pukrop, \& Rohling, 2006). However, another study, based on a relatively small sample comprising both healthy and pre-term children, reported no association between delayed motor and language milestones and attainment of nighttime bladder control (Largo, Molinari, von Siebenthal, \& Wolfensberger, 1999). It is also possible that there is an interaction between a child's maturational level and the impact of stress on the development of bedwetting, with children who suffer developmental delays showing increased vulnerability to psychosocial stress (Jarvelin et al.1991). Furthermore, maturational delay may increase risk for relapse (secondary enuresis) among those children who experience significant or prolonged environmental stressors. 
There is also some evidence that difficult child temperament traits are associated with delays in attaining continence. Temperament differences (e.g. less adaptability and more negative mood) have been found in children who experienced problems acquiring and maintaining daytime bladder and bowel control (Joinson, et al. 2008) and in those who were reported by their parents to be difficult to toilet train (Schonwald, Sherritt, Stadtler \& Bridgemohan, 2004). However, the evidence is inconsistent (Blum, Taubman \& Nemeth, 2004). Difficult temperament traits and little desire to co-operate with parents may lead to problems in the toilet training process. However, to date, studies of temperamentcontinence relations have been restricted to daytime continence and it is yet unknown whether difficult child temperament is also associated with problems attaining nighttime bladder control.

Also known to be influential are psychosocial and environmental factors in the family, linked to stress and early adversity (Kolvin \& Taunch, 1973; Douglas 1973; Fergusson, Horwood, \& Shannon, 1990; Jarvelin, Moilanen, Vikevainen-Tervonen, \& Huttunen, 1990; Kaffman \& Elizur, 1977; MacKeith, 1968; Stein \& Susser, 1967; Werry, 1967). One important form of psychosocial adversity in early childhood is exposure to maternal psychopathology. A large and expanding literature evidences the short and longterm effects of exposure to maternal depression and anxiety on child development (Cicchetti, Rogosch \& Toth, 1998; Downey \& Coyne, 1990; Ross \& McLean, 2006; Rutter, 1989). One early study of children with enuresis and their families reported a link between bedwetting and an increased rate of psychiatric disorders in the mothers (Hallgren, 1957), but this is yet to be investigated in a population-based study. The present study, based on almost 11,000 children from a UK birth cohort, has two main aims: (1) to further examine trajectories of child development to nighttime bladder control using latent class models, and (2) to test the hypotheses that the following risk factors will be associated with an increase in odds of bedwetting in school age children: child maturation/developmental delay; difficult child temperament and exposure to maternal psychopathology.

\section{Method}

\section{Participants}

The Avon Longitudinal Study of Parents and Children (ALSPAC) is a longitudinal, population-based, birth cohort study that recruited 14,541 pregnant women resident in Bristol, formerly in the county of Avon, UK with expected dates of delivery 1st April 1991 to 31st December 1992. There were 14,062 live born children. The study protocol and the representative nature of the ALSPAC sample have been described previously (Golding, Pembrey \& Jones, 2001). Further details are on the ALSPAC website: http://www.alspac.bris.ac.uk. Ethical approval for the study was obtained from the ALSPAC Law and Ethics Committee and the Local Research Ethics Committees. Data were collected using self-completion questionnaires sent to the mothers during pregnancy and approximately annually since the birth of the child. Direct assessments were carried out at annual research clinics from the age of 7 years.

\section{Measures}

Bedwetting: Questions relating to the child's bedwetting were asked regularly between 15 months and 9.5 years. We used data from the final five time points, where questions were phrased in such a way that the occurrence of bedwetting was considered unusual rather than normal ('How often usually does your child wet the bed at night?' as opposed to 'Is your child dry during the night?'). At 4.5 and 5.5 years the carer was asked about the frequency of the child's bedwetting: a) never; b) less than once a week; c) about once a week; d) more than once a week; e) every night. At 6.5, 7.5 and 9.5 years, options $(d)$ and (e) were reworded and three categories formed (2-5 times a week, nearly every night and more than once a night respectively. For the purpose of the analyses, we collapsed these categories into binary variables with 'yes' (1) indicating any level of bedwetting, compared to none (0).

Child Development: Maturation/developmental level at 18 months was assessed using a questionnaire developed by ALSPAC which included items from the Denver Developmental Screening Test (Frankenburg, Dodds, Archer, Shapiro \& Bresnick, 1992) comprising four domains (fine motor, $\alpha=$ 0.679 ; gross motor, $\alpha=0.689$; communication, $\alpha=0.752$ and social skills, $\alpha=0.624)$. Scales were adjusted for age in weeks, then standardized (using a linear regression model and extracting the 
residuals) and reversed where appropriate so that high values on all scores reflected a lower level of development.

Child temperament: The Toddler Temperament Scale (Fullard, McDevitt \& Carey, 1984) was administered at 24 months to assess nine temperamental traits (activity, $\alpha=0.593$; rhythmicity, $\alpha=$ 0.672; approach, $\alpha=0.848$; adaptability, $\alpha=0.637$; intensity, $\alpha=0.570$; mood, $\alpha=0.672$; persistence, $\alpha=0.711$; distractibility, $\alpha=0.712$, and threshold, $\alpha=0.517$ ). Scales were standardised, and reversed where appropriate so that high values on all scores reflected a more difficult temperament.

Maternal psychopathology: Maternal symptoms (anxiety and depression) were assessed when the study child was 21 months using 10 questions from the Edinburgh Postnatal Depression Scale ( $\alpha=0.867$; EPDS; Cox, Holden \& Sagovsky, 1987) together with the Crown-Crisp Experiential Index (previously known as the Middlesex Hospital Questionnaire) comprising anxiety $(\alpha=0.771)$; depression $(\alpha=0.706)$, and somatic symptoms $(\alpha=0.524)$ scales (CCEl; Crown \& Crisp, 1979; Crown, Duncan \& Howell, 1970). EPDS was dichotomized at a cut-off of 12/13, the standard cut-off used to indicate probable depressive disorder (Evans, Heron, Francomb, Oke \& Golding, 2001). All CCEI scales were highly skewed and hence were dichotomized. CCEI does not have a standard cut-off so the following were used: depression scale $-8 / 9$, anxiety scale $-8 / 9$, somatic symptoms scale $-5 / 6$. This ensured approximately $10 \%$ of cases fell above the cut-off, creating a group comparable in size to the EPDS group allowing easier comparison of regression estimates between the anxiety/depression measures. Further information on the child development, temperament and maternal psychopathology measures used in this study can be found in Joinson et al. 2008 - see supplementary data.

\section{Statistical modelling}

Repeated enuresis outcomes (binary) were modelled using latent variables in Mplus. The risk set eligible for these analyses consisted of 13,793 cohort members: 7,217 boys and 6,756 girls who were alive at 1 year of age. We identified the enuresis trajectories using a two-stage approach.

First, we estimated the trajectory groups using Longitudinal Latent Class Analysis (LLCA) then we compared and confirmed the results in Mplus Version 4.2 (Muthén \& Muthén, 1998-2006) and Latent GOLD 4.0 (Statistical Innovations, Inc., Belmont, MA). For the latent class analysis of nighttime bladder control, at least one parental report on whether their child wet the bed at night was required and available for 10,818 children. A complete set of parental report data i.e. from all five measurement occasions was available for 5,843 children.

Secondly, we used multinomial logistic regression in Stata Version 9.2 to examine the impact of categorical, grouped and continuous risk factors on the class membership probabilities (vulnerability factors). More details of the various stages of the modelling process are given below.

Stage 1: Estimation of trajectories: Longitudinal Latent Class Analysis (LLCA) is simply latent class analysis (LCA) applied to longitudinal data. As with the standard LCA model, there are unconditional probabilities that capture the class sizes in the latent typological classification, and a set of conditional probabilities, for each time-point in each class, that describe the trajectories of bedwetting in each group. Croudace et al. (2003) employed two types of model - longitudinal latent class analysis (LLCA) and latent class growth analysis (LCGA). Although the LCGA approach is more parsimonious, capturing curvilinear trends within class profiles and allowing restrictions on the shape of the outcome trajectories (polynomial trends on the logit-linear scale), LLCA was preferred because LCGA was unable to fit the shape of the bedwetting relapse class found in their dataset where there is a turning point. For further technical details see methods in Croudace et al. (2003) and appendix therein.

In the current study, we considered only the LLCA approach since we expected to recover similar trajectory shapes and were interested in replicating the analyses from this earlier cohort. For the same reason of replication we did not consider other models such as a growth mixture model, which had not been considered in the original paper, neither did we investigate the effect of frequency of bedwetting with the LLCA. There is robustness and simplicity in our binary repeated measures analysis since it is entirely semi-parametric. 
Model selection and assessment of model fit: All models were estimated using ML in Mplus 4.2 and we checked results against the log-likelihood achieved for the same model estimated in Latent GOLD 4. In both programs we used multiple random starts to help achieve the optimal maximum likelihood solution.

In order to select the 'optimal' model, we employed a number of different criteria. Statistics derived from the likelihood were considered: (i) the bootstrap p-values for the global likelihood ratio goodness of fit chi-square and (ii) the nested LR test p-values (based on bootstrap), both from Latent GOLD, in conjunction with (iii) the BLRT (Bootstrap Likelihood Ratio Test) (Nylund, Asparouhov, \& Muthen 2007) and (iv) the BIC (Bayesian Information Criterion) (Schwarz, 1978) from Mplus. Finally, an assessment of model classification (v) Entropy, was also inspected (Ramaswamy, DeSabro, Reibstein, \& Robinson, 1993). This is a single measure of the separation of the classes based on the posterior class membership probabilities. In addition, rather than basing the decision solely on statistical criteria, there are other aspects that should be considered including face validity, the resemblance to other results in the literature, as well as the diminishing returns of adding additional classes.

Stage 2: Multinomial modelling of contributing factors and bedwetting trajectories: Once the optimal LLCA model had been established, we used a variable representing trajectory group membership as the outcome in an examination of the contributing factors that might distinguish between normal and atypical development of nighttime bladder control. This was achieved using a set of multinomial regression models in which the odds ratios were estimated free of any constraints (mlogit) and derived in relation to the normative trajectory group, which was used as the reference group in all analyses of contributing factor associations.

In the two-stage approach (class derivation followed by covariate modelling) followed here, a nonweighted multinomial analysis using an outcome derived from modal class assignment is sub-optimal, as any uncertainty in class membership is ignored. Consequently, we reshaped the dataset so that there were five data points for each child, indicating the posterior probability assignment to each latent class. We then used the posterior probabilities as a weighting variable using Stata's iweight subcommand. For example, if a particular child was assigned a probability of 0.6 for class 1 and 0.1 for the four remaining classes, then the class 1 observation would be given six times the weight in the analysis. Bootstrapping was employed during preliminary work to sample from each child's distribution of posterior probabilities and this demonstrated that standard errors obtained using the iweights approach was accurate (details available on request).

Adjustment for confounders: We adjusted regression estimates for gender and a number of indicators of socio-demographic level that were recorded from information available during the first two years of the study child's life. This information enabled simple definitions for binary and nominal covariates for early parenthood, housing adequacy, maternal education, financial difficulties, family size, partner support, and the presence of an emotional support network. Finally, we note that further adjustment was made for intellectual disability $(\mathrm{IQ}<70)$ obtained from assessment at a research clinic the children attended at eight years, using the Wechsler Intelligence Scale for Children Third Edition- WISC-III; Wechsler, Golombok \& Rust, 1992) due to the possibility that low IQ may be associated with both delayed attainment of nighttime continence as well as with the early childhood contributing factors detailed above. In a previous paper (Joinson et al. 2008) we carried out both methods (adjusting and excluding) due to the possibility that any of the observed associations were being driven by the low IQ subgroup. Due to the small size of the excluded group $(n=114)$, the class distributions across the sample as a whole remained unaffected by this exclusion and the effect on the regression estimates of removing these children was negligible. We, therefore, decided that adjusting for $\mathrm{IO}<70$ would be appropriate in the current paper, because we did not expect any major changes in the results if these children were excluded. We did not take account of prescribed medicines (e.g. those prescribed for behaviour problems) because this comprised a very small number of children and is unlikely to affect the results. 


\section{Results}

The risk set eligible for these analyses consisted of 13,793 cohort members: 7,217 boys and 6,756 girls who were still alive at 1 year of age. For the latent class analysis of nighttime bladder control, at least one parental report on whether their child wet the bed at night was required and available for 10,818 children. A complete set of parental report data i.e. from all five measurement occasions was available for 5,843 children.

The marginal prevalence of bedwetting outcomes and missing data at each age is shown in Table 1. Percentages refer to children who wet the bed as a proportion of the responding sample. The prevalence of bedwetting declined at each age from $30 \%$ at 4.5 years to $9.7 \%$ at 9.5 years of age. Rates for boys were higher across the full five-year observation period and level of non-response increases steadily as the child ages.

Table 1. The marginal prevalence and percentage missing data

\begin{tabular}{l|l|l|l|l|l}
\hline & 4.5 years & 5.5 years & 6.5 years & 7.5 years & 9.5 years \\
\hline Boys $(\boldsymbol{n}=\mathbf{7 2 1 7})$ & & & & & \\
\hline No bedwetting & 3139 & 3309 & 3293 & 3370 & 3414 \\
\hline Bedwetting & $1793(36.4 \%)$ & $1281(27.9 \%)$ & $1061(24.4 \%)$ & $844(20.0 \%)$ & $526(13.4 \%)$ \\
\hline No response & 2285 & 2627 & 2863 & 3003 & 3277 \\
\hline Girls $(\boldsymbol{n}=\mathbf{6 7 5 6})$ & & & & & \\
\hline No bedwetting & 3555 & & & & \\
\hline Bedwetting & $1074(23.2 \%)$ & $691(16.0 \%)$ & $586(14.3 \%)$ & $420(10.6 \%)$ & $225(5.9 \%)$ \\
\hline No response & 2127 & 2430 & $2654)$ & 2776 & 2944 \\
\hline
\end{tabular}

\section{Deriving the nighttime bladder control trajectory classes:}

Model fit statistics for three, four and five-class models fitted on complete and partially missing datasets are shown in Table 2.

Table 2. Model fit statistics for longitudinal latent class analysis (LLCA) three, four and five-class models fitted on complete $(\mathrm{N}=5,843)$ and partially complete $(\mathrm{N}=10,818)$ samples.

\begin{tabular}{l|l|l|l|l|l|l}
\hline & \multicolumn{3}{l|}{ Complete case analyses } & \multicolumn{2}{l}{ Models with partially missing data } \\
\hline & 3 class & 4 class & 5 class & 3 class & 4 class & 5 class \\
\hline Latent GOLD BS (Global) & $<0.0001$ & 0.2124 & 0.4788 & $<0.0001$ & 0.0088 & 0.0152 \\
\hline Latent GOLD BS (Nested) $^{*}$ & $<0.0001$ & $<0.0001$ & 0.1424 & $<0.0001$ & $<0.0001$ & 0.1148 \\
\hline Mplus BLRT* & $<0.0001$ & $<0.0001$ & 0.1700 & $<0.0001$ & $<0.0001$ & 0.2200 \\
\hline Mplus BIC & 20548.0 & 20505.7 & 20548.9 & 31833.3 & 31788.3 & 31835.7 \\
\hline Mplus Entropy & 0.824 & 0.844 & 0.804 & 0.760 & 0.782 & 0.755 \\
\hline
\end{tabular}

${ }^{*}$ Results compare current model to one with one less class

Whilst BIC (Bayesian Information Criterion) and entropy favoured the 4-class model, and the BLRT showed that the 5-class model did not significantly improve on the fit of the 4-class model, the bootstrap tests obtained via Latent GOLD suggested that the 5-class model was marginally better. We decided that both 4- and 5-class models were supported by these data and should be considered. Entropy values were high for the complete-case models, and lower but acceptable for the models with partially missing data. Trajectory shapes for the 4-class model are shown in Figure 1. 
Figure 1. Longitudinal bedwetting patterns for the 4-class model, complete case sample $(n=5,843)$.

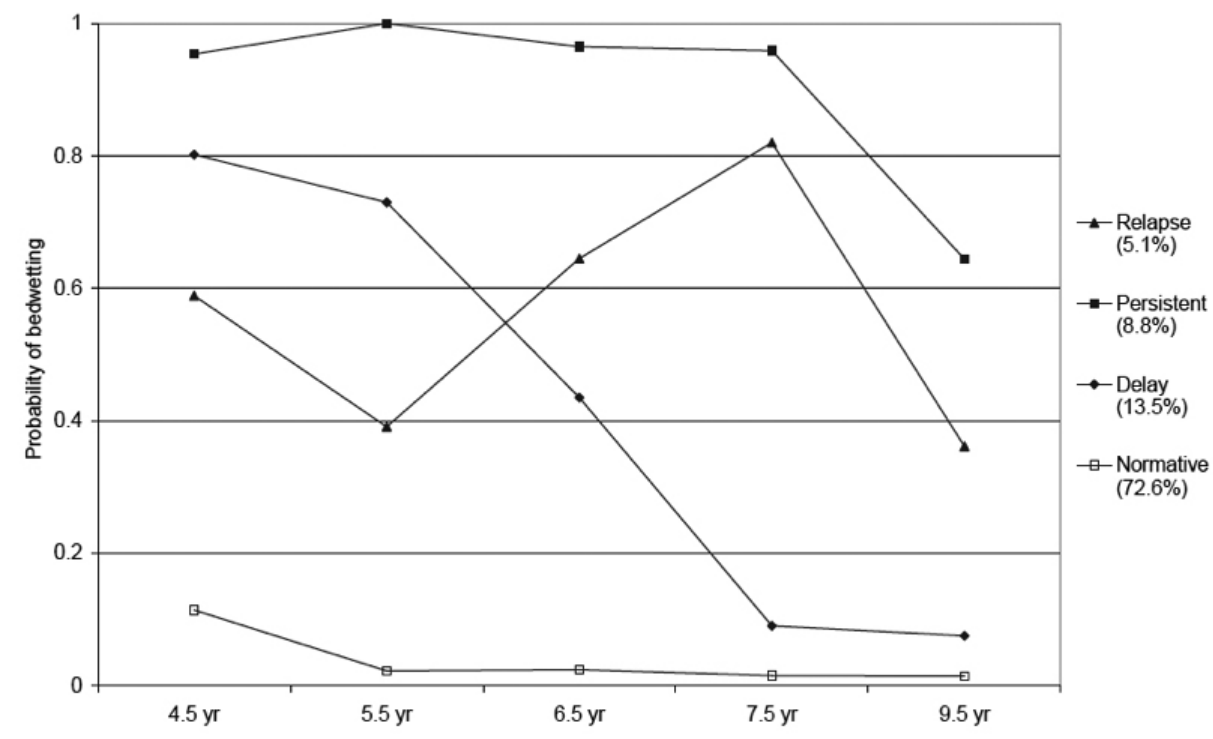

According to the 4-class model, the prevalence of normative development of nighttime bladder control was $72.6 \%$ in children whose parents had reported on all five measurement occasions. The next largest class (prevalence 13.5\%) experienced a delay in attaining nighttime bladder control, and a smaller class (prevalence 8.8\%) experienced persistent problems into later childhood. The fourth and smallest class (prevalence 5.1\%) attained nighttime bladder control later than the normative class, and were prone to relapse i.e. had onset of a problem after partial success in attaining nighttime bladder control.

Extraction of a fifth trajectory class in the enlarged sample (including children with some missing data) resulted in further refinement of the perspective of the mixture model on population heterogeneity Figure 2. Here the normative development class was reduced in size due to the identification of a second delayed class: one that followed a trajectory more similar to normative development than the delayed class from the 4-class model $(8.4 \%)$ and one that was similar to the group with persistent problems $(9.3 \%)$. The prevalence of the persistent group remained around one in ten children (8.6\%).

Figure 2. Longitudinal bedwetting patterns for the 5-class model, partially missing sample $(n=10,818)$.

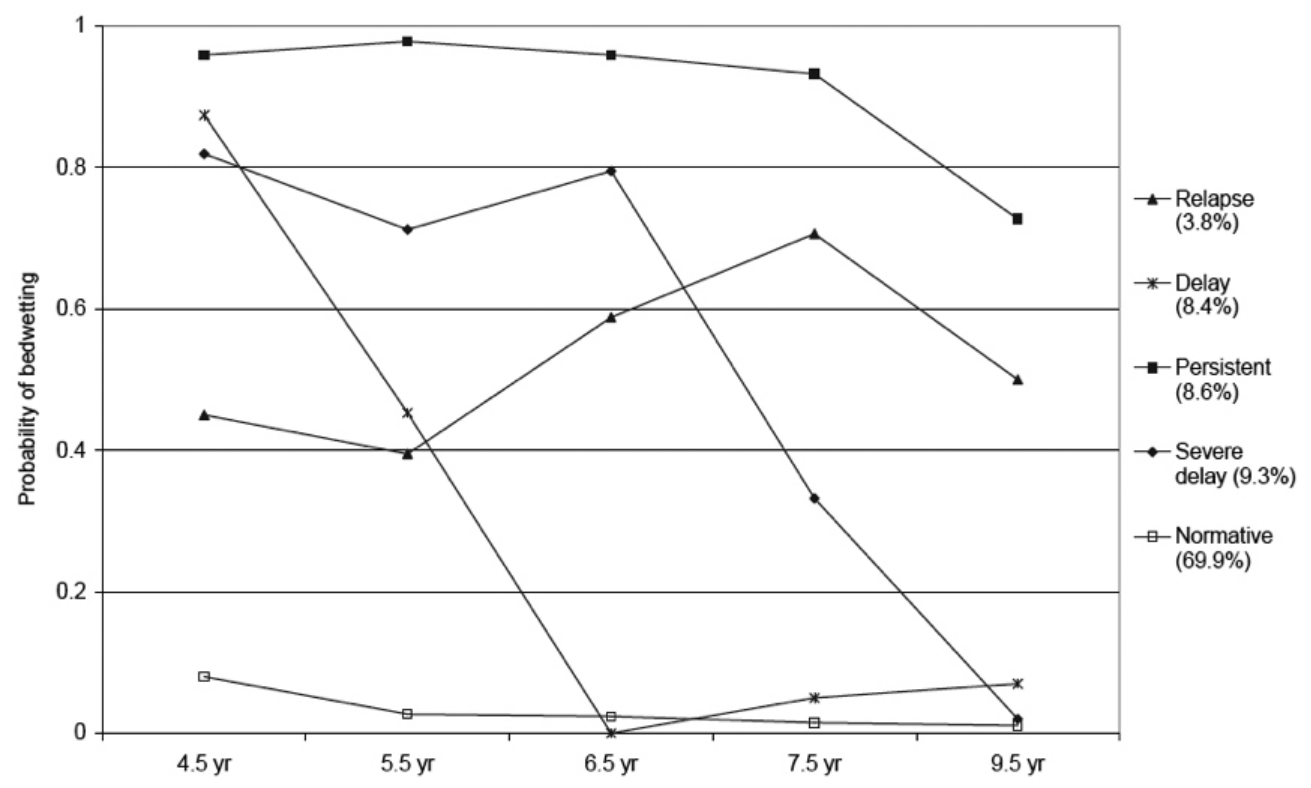


We favoured the five-class model obtained with the partially missing sample $(n=10,818)$ over the fourclass model because of the resemblance to the findings of Croudace et al. (2003) who argued that the bedwetting trajectories they identified were consistent with current diagnostic conceptualizations of primary and secondary enuresis. The labels assigned to the five classes were as follows: (1) normative $(69.9 \%$ of 10,818 sample): a class with a very low probability of a bedwetting event throughout the time period; (2) delayed (8.4\%): a class with a high probability of bedwetting at 4.5 years falling quickly to a very low probability from 6.5 years onwards; (3) severely delayed $(9.3 \%)$ : a class with a high probability of bedwetting until 6.5 years, which then begins to diminish; (4) the persistent class $(8.6 \%)$ have a very high probability of bedwetting throughout the time period, and finally (5) the relapse class $(3.8 \%)$ have an initially decreasing probability of bedwetting but with a secondary peak at 7.5 years, after which the probability of bedwetting decreases. The naming convention for the bedwetting trajectories used by Croudace et al. (2003) was not adopted in the current study to make this work consistent with a previous study of trajectories of daytime wetting and soiling in the ALSPAC cohort (Heron et al. 2008).

Gender differences and rates of bedwetting at DSM-IV frequency: The prevalence varied by gender with a disproportionately high number of boys present in all non-normative trajectory classes (Table 3 ). These figures were derived following assignment of each child to their modal class, i.e. the class for which their posterior probability was greatest. The gender ratio was highest in the persistent and relapse classes where boys out-numbered girls by 2.10:1 and 2.13:1 respectively. Although these trajectories were derived whilst ignoring the frequency of the reported bedwetting events, the second half of Table 3 shows that there is a strong relationship between the grouping and the frequency of bedwetting, with the rates of bedwetting twice or more per week (frequency required for DSM-IV diagnosis) being much higher within the persistent wetting group and very low among the relapsing children.

Table 3. Gender ratios within class and the rates of bedwetting twice or more per week

\begin{tabular}{llllll}
\hline Latent Class & 1 & 2 & 3 & 4 & 5 \\
\hline Class Label & Normative & Delayed & Severe delay & Persistent & Relapse \\
\hline Boys & $47.4 \%$ & $58.0 \%$ & $62.9 \%$ & $67.7 \%$ & $68.1 \%$ \\
\hline Girls & $52.6 \%$ & $42.0 \%$ & $37.1 \%$ & $32.3 \%$ & $31.9 \%$ \\
\hline Gender ratio & 0.90 & 1.38 & 1.70 & 2.10 & 2.13 \\
\hline
\end{tabular}

Rates of bedwetting twice or more per week

\begin{tabular}{llllll}
\hline 4.5 years & $1.1 \%$ & $20.8 \%$ & $23.3 \%$ & $35.0 \%$ & $4.4 \%$ \\
\hline 5.5 years & $0.1 \%$ & $8.0 \%$ & $14.2 \%$ & $30.1 \%$ & $2.7 \%$ \\
\hline 6.5 years & $0.0 \%$ & $0.0 \%$ & $6.0 \%$ & $23.0 \%$ & $3.3 \%$ \\
\hline 7.5 years & $0.0 \%$ & $0.0 \%$ & $1.4 \%$ & $16.6 \%$ & $2.7 \%$ \\
\hline 9.5 years & $0.0 \%$ & $0.2 \%$ & $0.0 \%$ & $8.6 \%$ & $3.3 \%$ \\
\hline
\end{tabular}

\section{Multinomial modelling of the bedwetting trajectories and early life contributing factors}

The covariates described earlier were used in a set of multinomial logistic models to assess the odds of a child belonging to each of the atypical classes. Since the model fit criteria, trajectory shapes and class distributions were very consistent for the complete case and partially missing samples, this analysis focused on the results from the larger sample. Incorporation of predictor variables resulted in a $10-15 \%$ reduction in sample size (individual sample sizes are stated within tables 4 a to 4c). Previous work (Butler \& Heron, 2008) has shown that there is little evidence of a relationship between bedwetting and predictors of 'missingness' so we felt that the reduction in sample size would have little influence on the overall findings. We fitted the models on samples where there were trajectory outcomes (derived from partially missing bedwetting data) in addition to data available on each individual contributing factor and confounders. 
Tables 4a to 4c show the results of the multinomial models of the association between the contributing factors (development; temperament; exposure to maternal depression and anxiety) and the different trajectories of nighttime bladder control (delayed, severe delay, persistent and relapse). The tables show both unadjusted and adjusted odds ratios and 95\% confidence intervals (models adjusted for gender, $\mathrm{IQ}<70$ and indices of social adversity - including items on early parenthood, housing adequacy, maternal education, financial difficulties, family size, partner support, and the presence of an emotional support network). Odds ratios were derived in relation to the normative trajectory of nighttime bladder control (used as the reference group). For continuous contributing factors (development and temperament), regression estimates are for a 1 SD increase in the covariate. P-values shown are for a global test of differences across the five outcome groups i.e. the null hypothesis is that all four odds ratios shown are equal to unity.

\section{Delayed, severely delayed and persistent bedwetting trajectories}

Child development: Table 4a shows strong evidence for an effect in all domains of developmental level ( $p<0.001$ throughout for the unadjusted models). There is an apparent trend in odds ratios across the delayed, severely delayed and persistent bedwetting groups. For example, in the unadjusted model, there was a $14 \%$ increased odds of following a delayed bedwetting trajectory for each SD change in the total development score, whereas the percentage increased risks for the severely delayed and persistent groups were $22 \%$ and $29 \%$ respectively. Restricted models were fitted to examine whether it was possible to assume a linear relationship through these 4 outcome levels (normative/delayed/severely-delayed/persistent) whilst estimating an additional estimate for the relapse group. Chi-square values (-2* change in likelihood) along with $\mathrm{p}$-values were as follows: fine motor (chi ${ }^{2}$ $<0.01, p=0.996)$, gross motor $\left(\mathrm{chi}^{2}=0.06, \mathrm{p}=0.814\right)$, communication $\left(\mathrm{chi}^{2}<0.01\right.$, $\left.\mathrm{p}=0.984\right)$, social skills $\left(\mathrm{chi}^{2}=0.13, \mathrm{p}=0.715\right)$ and total development $\left(\mathrm{chi}^{2}=0.01, \mathrm{p}=0.942\right)$ i.e. in support of the linear trend for these groups. Adjustment for confounders led to considerable attenuation of these effects (particularly due to gender differences), however there was still strong evidence for an association with communication, gross motor skills, social skills and total development.

Table 4a. Association of trajectories of nighttime bladder control with domains of developmental level - odds ratios for a one standard deviation drop in age-adjusted development scores.

\begin{tabular}{lllllll}
\hline & $\mathrm{n}$ & Delayed & Severe delay & Persistent & Relapse & $\mathrm{p}$ \\
\hline Fine motor & \multicolumn{7}{c}{} & & & \\
\hline Unadjusted OR & 9626 & $1.05[0.99,1.10]$ & $1.09[1.04,1.15]$ & $1.14[1.08,1.21]$ & $1.07[1.01,1.14]$ & $<0.001$ \\
\hline Adjusted OR & 9103 & $1.02[0.96,1.08]$ & $1.06[1.01,1.12]$ & $1.09[1.02,1.17]$ & $1.03[0.96,1.10]$ & 0.040 \\
\hline
\end{tabular}

\section{Gross motor}

\begin{tabular}{llllllll}
\hline Unadjusted OR & 9622 & $1.08[1.02,1.13]$ & $1.10[1.05,1.16]$ & $1.15[1.09,1.22]$ & $1.10[1.04,1.16]$ & $<0.001$ \\
\hline Adjusted OR & 9100 & $1.08[1.02,1.14]$ & $1.11[1.05,1.17]$ & $1.16[1.09,1.23]$ & $1.10[1.04,1.17]$ & $<0.001$ \\
\hline
\end{tabular}

\section{Communication}

\begin{tabular}{llllllll}
\hline Unadjusted OR & 9633 & $1.11[1.06,1.17]$ & $1.19[1.13,1.25]$ & $1.26[1.19,1.35]$ & $1.17[1.10,1.25]$ & $<0.001$ \\
\hline Adjusted OR & 9109 & $1.05[1.00,1.11]$ & $1.11[1.05,1.18]$ & $1.15[1.07,1.23]$ & $1.09[1.01,1.17]$ & $<0.001$ \\
\hline
\end{tabular}

Social

\begin{tabular}{llllllll}
\hline Unadjusted OR & 9624 & $1.14[1.09,1.20]$ & $1.19[1.13,1.26]$ & $1.21[1.14,1.29]$ & $1.13[1.06,1.20]$ & $<0.001$ \\
\hline Adjusted OR & 9101 & $1.11[1.05,1.17]$ & $1.14[1.08,1.21]$ & $1.14[1.06,1.22]$ & $1.07[0.99,1.14]$ & $<0.001$ \\
\hline
\end{tabular}

Total development

\begin{tabular}{llllllll}
\hline Unadjusted OR & 9608 & $1.14[1.09,1.20]$ & $1.22[1.16,1.28]$ & $1.29[1.21,1.37]$ & $1.18[1.11,1.25]$ & $<0.001$ \\
\hline Adjusted OR & 9087 & $1.10[1.04,1.16]$ & $1.16[1.10,1.23]$ & $1.20[1.12,1.28]$ & $1.11[1.03,1.18]$ & $<0.001$ \\
\hline
\end{tabular}

Estimates for each atypical class of the outcome are referenced against the normative class. 
Child temperament: Table 4b shows evidence for associations between several child temperament domains and the atypical trajectories of nighttime bladder control. In particular, there was evidence for an effect in the temperament domains of activity, adaptability, intensity, mood, persistence, and threshold. There was an increase in odds across the delayed, severely delayed and persistent bedwetting groups, with the exception of the activity domain where the odds were similar across the trajectories. Once again the assumption of a trend across certain outcome levels was upheld within these models. The only outcome for which the change in likelihood was moderately large was for mood with a chi2 of $0.60(p=0.441)$ providing little evidence for a deviation from a linear relationship. Following adjustment for confounders there was still evidence for associations within the temperament domains (with the exception of the threshold domain where the odds ratios were considerably weakened).

Table 4b. Association of trajectories of nighttime bladder control with temperament traits - odds ratios for a one standard deviation increase in difficult temperament scores.

\begin{tabular}{lllllll}
\hline & $\mathrm{n}$ & Delayed & Severe delay & Persistent & Relapse & $\mathrm{p}$ \\
\hline Activity & & & & & \\
\hline Unadjusted OR & 9580 & $1.11[1.05,1.16]$ & $1.14[1.08,1.20]$ & $1.12[1.05,1.19]$ & $1.13[1.06,1.20]$ & $<0.001$ \\
\hline Adjusted OR & 9079 & $1.08[1.02,1.14]$ & $1.11[1.05,1.17]$ & $1.08[1.01,1.16]$ & $1.10[1.03,1.18]$ & $<0.001$ \\
\hline Rhythmicity & & & & & \\
\hline Unadjusted OR & 9577 & $1.01[0.96,1.07]$ & $1.03[0.97,1.08]$ & $1.03[0.97,1.10]$ & $0.98[0.92,1.05]$ & 0.708 \\
\hline Adjusted OR & 9077 & $1.01[0.96,1.07]$ & $1.04[0.98,1.09]$ & $1.03[0.97,1.10]$ & $0.99[0.92,1.06]$ & 0.596 \\
\hline
\end{tabular}

Approach

\begin{tabular}{lllllll}
\hline Unadjusted OR & 9577 & $0.97[0.92,1.02]$ & $0.97[0.91,1.02]$ & $0.99[0.93,1.06]$ & $0.95[0.89,1.01]$ & 0.420 \\
\hline Adjusted OR & 9077 & $0.98[0.93,1.03]$ & $0.99[0.93,1.04]$ & $1.02[0.95,1.09]$ & $0.99[0.93,1.06]$ & 0.868
\end{tabular}

Adaptability
\begin{tabular}{llllllll}
\hline Unadjusted OR & 9539 & $1.15[1.09,1.20]$ & $1.17[1.11,1.24]$ & $1.23[1.16,1.31]$ & $1.18[1.11,1.26]$ & $<0.001$ \\
\hline Adjusted OR & 9045 & $1.12[1.06,1.18]$ & $1.15[1.09,1.22]$ & $1.19[1.11,1.27]$ & $1.16[1.09,1.25]$ & $<0.001$
\end{tabular}

Intensity

\begin{tabular}{lllllll}
\hline Unadjusted OR & 9574 & $1.07[1.01,1.12]$ & $1.12[1.06,1.18]$ & $1.15[1.08,1.23]$ & $1.15[1.07,1.23]$ & $<0.001$ \\
\hline Adjusted OR & 9075 & $1.05[1.00,1.11]$ & $1.11[1.05,1.17]$ & $1.14[1.06,1.21]$ & $1.14[1.06,1.22]$ & $<0.001$ \\
\hline
\end{tabular}

Mood

\begin{tabular}{lllllll}
\hline Unadjusted OR & 9580 & $1.13[1.08,1.19]$ & $1.12[1.06,1.18]$ & $1.18[1.11,1.26]$ & $1.14[1.07,1.21]$ & $<0.001$ \\
\hline Adjusted OR & 9080 & $1.12[1.06,1.18]$ & $1.12[1.06,1.18]$ & $1.17[1.10,1.25]$ & $1.15[1.08,1.22]$ & $<0.001$ \\
\hline Persistence & & & & & & \\
\hline Unadjusted OR & 9572 & $1.12[1.06,1.18]$ & $1.15[1.09,1.21]$ & $1.18[1.11,1.25]$ & $1.17[1.10,1.25]$ & $<0.001$ \\
\hline Adjusted OR & 9075 & $1.10[1.05,1.16]$ & $1.14[1.07,1.20]$ & $1.14[1.07,1.22]$ & $1.15[1.07,1.23]$ & $<0.001$ \\
\hline
\end{tabular}

\section{Distractibility}

\begin{tabular}{lllllll}
\hline Unadjusted OR & 9577 & $1.01[0.96,1.06]$ & $1.04[0.99,1.10]$ & $1.09[1.02,1.16]$ & $1.01[0.94,1.07]$ & 0.081 \\
\hline Adusted OR
\end{tabular}

\begin{tabular}{lllllll}
\hline Adjusted OR & 9077 & $1.00[0.95,1.05]$ & $1.02[0.96,1.07]$ & $1.06[0.99,1.13]$ & $0.99[0.92,1.06]$ & 0.464
\end{tabular}

\section{Threshold}

\begin{tabular}{lllllll}
\hline Unadjusted OR & 9581 & $1.07[1.02,1.12]$ & $1.07[1.02,1.13]$ & $1.12[1.06,1.19]$ & $1.08[1.02,1.15]$ & $<0.001$ \\
\hline Adjusted OR & 9081 & $1.04[0.99,1.10]$ & $1.03[0.97,1.08]$ & $1.05[0.98,1.11]$ & $1.04[0.97,1.10]$ & 0.372 \\
\hline
\end{tabular}

Estimates for each atypical class of the outcome are referenced against the normative class. 
Maternal psychopathology: For the maternal depression/anxiety measures, there was evidence for an effect in three of the domains (EPDS depression; CCEI anxiety; CCEI depression) (Table 4c). Trends across the delayed, severely delayed and persistent groups were less apparent for the maternal depression/anxiety measures and there was little evidence for ranking between the severe delay and persistent groups. Although it appeared that a linear effect would not adequately describe the relationship shown in these results, examination of changes in likelihood provided little evidence for a deviation from a linear relationship: EPDS $\left(\mathrm{chi}^{2}=0.60, \mathrm{p}=0.441\right)$, anxiety $\left(\mathrm{chi}^{2}=0.01, \mathrm{p}=0.940\right)$, depression $\left(\mathrm{chi}^{2}=0.90, \mathrm{p}=0.342\right)$, somatic symptoms $\left(\mathrm{chi}^{2}=0.61, \mathrm{p}=0.435\right)$.

Table 4c. Association of trajectories of nighttime bladder control with maternal depression and anxiety measures odds ratios for scores above the cut-offs on the Edinburgh Post Natal Depression Scale and the Crown Crisp Experiential Index scales for depression, anxiety and somatic symptoms.

\begin{tabular}{|c|c|c|c|c|c|c|}
\hline & $\mathrm{n}$ & Delayed & Severe delay & Persistent & Relapse & $\mathrm{p}$ \\
\hline \multicolumn{7}{|c|}{ Edinburgh Post Natal Depression Scale (EPDS) } \\
\hline Unadjusted OR & 9452 & $1.01[0.85,1.20]$ & $1.30[1.10,1.55]$ & $1.37[1.12,1.67]$ & $1.36[1.11,1.68]$ & $<0.001$ \\
\hline Adjusted OR & 9093 & $0.96[0.79,1.15]$ & $1.30[1.08,1.57]$ & $1.23[0.99,1.53]$ & $1.27[1.02,1.59]$ & 0.008 \\
\hline
\end{tabular}

Crown Crisp Experiential Index (CCEI) anxiety score

\begin{tabular}{llllllll}
\hline Unadjusted OR & 9327 & $1.09[0.92,1.29]$ & $1.21[1.02,1.43]$ & $1.31[1.07,1.59]$ & $1.37[1.12,1.67]$ & 0.003 & \\
\hline Adjusted OR & 8981 & $1.07[0.89,1.28]$ & $1.23[1.02,1.47]$ & $1.24[1.00,1.53]$ & $1.35[1.09,1.68]$ & 0.016 & \\
\hline
\end{tabular}

CCEI depression score

\begin{tabular}{lllllll}
\hline Unadjusted OR & 9394 & $1.01[0.84,1.21]$ & $1.35[1.12,1.62]$ & $1.38[1.12,1.70]$ & $1.26[1.02,1.56]$ & $<0.001$ \\
\hline Adjusted OR & 9044 & $0.97[0.80,1.19]$ & $1.38[1.14,1.69]$ & $1.27[1.01,1.61]$ & $1.21[0.97,1.52]$ & 0.004 \\
\hline
\end{tabular}

CCEI somatic score

\begin{tabular}{|c|c|c|c|c|c|c|}
\hline Unadjusted OR & 9410 & $1.03[0.86,1.22]$ & $1.02[0.85,1.22]$ & $1.28[1.04,1.57]$ & $1.23[0.99,1.53]$ & 0.087 \\
\hline Adjusted OR & 9055 & $0.99[0.82,1.20]$ & $0.97[0.80,1.17]$ & $1.13[0.91,1.41]$ & $1.18[0.93,1.50]$ & 0.487 \\
\hline
\end{tabular}

Estimates for each atypical class of the outcome are referenced against the normative class. EPDS depression score above a cut-off of 12/13; CCEI scale scores above the following cut-offs: depression $-8 / 9$, anxiety $-8 / 9$, somatic symptoms $-5 / 6$.

Bedwetting relapse trajectory: There was also evidence for an association between some of the early life contributing factors and the trajectory that represents relapse in bedwetting. For each SD change in the domains of developmental level, there was a $7-18 \%$ increased odds of following a bedwetting relapse trajectory, with similar odds for the temperament domains of activity, adaptability, intensity, mood, persistence, and threshold. However, for the maternal depression/anxiety measures, the association was stronger, with a $23-37 \%$ increased odds of following a bedwetting relapse trajectory for each SD change in each depression/anxiety domain.

Co-morbidity with daytime wetting and soiling: Previous results (Joinson et al. 2008) have shown a strong relationship between the contributing factors considered here and trajectories of both daytime wetting and soiling. It was surprising to see that to a large extent the results discussed in the current manuscript mirror those already reported. Due to the well-established association between bedwetting and daytime wetting/soiling (von Gontard \& Hollmann, 2004), it was considered important to ascertain whether the results reported above were being driven by this co-morbidity. Consequently, the results were further adjusted for membership of both atypical daytime wetting and soiling trajectory classes (results not shown but available from corresponding author). As expected, there was a further reduction in the odds ratios associated with the early life contributing factors, however, there was still evidence for an association with many of the factors considered. This suggests that the association between the bedwetting trajectories and the contributing factors cannot be fully explained by the association between the contributing factors and daytime wetting/soiling. There is still evidence for an 
association between the contributing factors and problems attaining (or maintaining) nighttime continence. This is even after taking into account that these contributing factors are also associated with daytime continence problems that often co-occur with bedwetting.

\section{Discussion}

This study based on a large UK birth cohort, applied latent class models to longitudinal data comprising parental reports of bedwetting from 4 - 9 years. Children were classified with respect to delay in attainment of nighttime bladder control, persistence of bedwetting, and secondary onset or relapse in bedwetting. Variations in normal development, occurring before the first measurement of problem wetting were not modelled, and hence a morbidity-oriented approach is adopted, that conforms closely to that applied by Croudace et al. (2003). Having established this congruence, the study then examined variation in membership probabilities for these empirically based, bedwetting classes by three key early life risks. All contributing factors related to characteristics of the child (maternal reports of maturation/developmental level at 18 months and child temperament traits at 24 months) or the mother (self-reported maternal anxious and depressive psychopathology experienced when the child was around 21 months old).

Using a larger and more recent cohort of UK children, but employing the same group-based (latent class) analytical approach the current study results presented four and five class models with similar profiles to those reported by the Croudace et al. (2003) typology. It is extremely rare for complex statistical models hypothesizing population heterogeneity to be tested on almost identical data in more than one sample with similar high quality prospective data; this is particularly the case when the questions of interest concern developmental outcomes for thousands of children, representative of the population in a defined geographical area.

The current study extended previous work by examining the associations between the contributing factors in early childhood and the developmental trajectories of nighttime bladder control. Of the three areas of risk considered, all were shown to be associated with problems attaining or maintaining continence, consistent with our hypotheses.

\section{Child Development}

Children who were reported by their parents to have developmental delays at 18 months had increased odds of bedwetting at school age, with a trend for increasing odds ratios across the delayed, severely delayed and persistent bedwetting groups. Bedwetting has been previously described as a genetically determined maturational disorder of the CNS (von Gontard, Schmelzer, Seifen, \& Pukrop, 2001) and this is supported by studies reporting evidence that developmental immaturity may play a part in the aetiology of bedwetting (Essen \& Peckham, 1976; Fergusson et al. 1986; Jarvelin, 1989; Jarvelin et al. 1991; Kawauchi et al. 2001; Touchette et al. 2005; von Gontard et al. 2006). A recent study, finding differences in intellectual capacities between children with and without bedwetting in the ALSPAC cohort, also underlines the importance of neurological factors (Joinson et al. 2007a). The specific factors relating to the CNS include polyuria (Rittig, Knudsen, Norgaard, Pedersen, \& Djurhuus, 1989), lack of arousal (Wolfish, Pivik \& Busby, 1997) and failure to inhibit the micturition reflex during sleep (Ornitz et al. 1999; Koff, 1996). The first mechanism is mediated by antidiuretic hormone secreted from the CNS, whilst the latter two mechanisms are mediated by the brainstem. The increased odds of maturational/developmental delays in children with bedwetting in the current study (particularly those with persistent bedwetting) are likely to be a manifestation of an underlying neurological deficit that is also linked to the inability to control nighttime micturition.

There was also some evidence for an association between developmental delay and relapse in bedwetting (although the odds ratios were smaller), suggesting a common underlying aetiology for primary and secondary (relapse) bedwetting. This view is supported by Fergusson et al. (1990) and Jarvelin (1989) who argue that both primary (never achieved nighttime bladder control for at least six consecutive months) and secondary enuresis (achieved nighttime bladder control for at least six months, and then suffers a relapse in bedwetting) are aspects of the same problem and share a common aetiological basis. They suggest that primary enuresis is due to delayed maturation of the physiological mechanisms controlling nighttime micturition and that, in the case of children who 
achieve nighttime bladder control and then experience relapse, this could be due to an underlying susceptibility to bedwetting provoked by stressful experiences.

\section{Child temperament}

This is the first study that we are aware of to investigate the association between bedwetting and early child temperament. There was evidence for more difficult temperament traits, rated by parents at 24 months, in children with delayed acquisition of nocturnal bladder control, persistent bedwetting and relapse in bedwetting. Children who were bedwetting between the ages of four and nine years were more likely at 24 months to be reported by mothers to have a higher activity level (e.g. fidgeting during quiet activities); were less adaptable (e.g. less likely to be coaxed out of a forbidden activity); had a higher intensity level i.e. more intense emotional reactions (e.g. screams or yells when frustrated); were more negative in mood (e.g. fretting or crying when learning a new task), and had lower levels of persistence i.e. were more easily frustrated and likely to give up activities (e.g. routine tasks such as dressing and picking up toys). These findings are supported by earlier studies describing certain 'personality features' of children with enuresis, including more irritability and less compliance (Moilanen, Järvelin, Vikevaeinen-Tervonen, \& Hunttunen, 1987) and lower patience and tolerance, more difficulties with concentration, and inappropriate behaviour (Srivastava, Nigam \& Sing, 1982).

Early difficult temperament has been found to be related to the development of externalizing and internalizing problems later on in childhood (Muris \& Ollendick, 2005; Oldehinkel, Hartman, De Winter, Veenstra \& Ormel, 2004). Moreover, there is evidence that bedwetting is associated with externalizing and internalizing problems in school age children in the ALSPAC cohort (Joinson, Heron, Emond \& Butler, 2007b), suggesting that early difficult temperament traits could be precursors to these later problems. In particular, co-morbidity between bedwetting and attention and activity problems has been widely reported (Baeyens, Roeyers, Van Erdeghem, Hoebeke \& Vande Walle, 2007; Joinson et al. 2007b). It is particularly notable that the odds ratios for the temperament trait of higher activity were similar across the trajectories, in comparison to the findings for the other temperament traits, where there was a general increase in odds across the delayed, severely delayed and persistent bedwetting groups. The link between higher activity levels reported in children at 24 months and subsequent bedwetting at school age could be due to a common underlying neurological deficit in the basic inhibitory function of the brainstem that also leads to an inability to inhibit the micturition reflex during sleep.

Another possible mechanism through which child temperament may impact on the development of nighttime bladder control is through parents having more negative perceptions of a child who has difficult temperament. Parents who rated their child as having difficult temperament at age 2 years may have been more likely to attribute subsequent bedwetting to the child's difficult behaviour or lack of cooperation with their attempts to encourage nighttime bladder control. Such negative reactions could have led to anxiety and stress, which have been shown to be associated with problems attaining nighttime bladder control (Houts, 1991). Some support for this argument comes from a finding in the ALSPAC cohort that parents of children who were still wetting the bed at age seven were more likely to report that they had shown displeasure at their child's bedwetting in the past compared to parents of children who were dry at night (Butler, Golding \& Northstone, 2005). It is not uncommon for parents to become intolerant of their child's bedwetting and resort to punitive actions, especially if they believe that the child is to blame (Butler, Redfern \& Forsyth, 1993).

\section{Maternal psychopathology}

The current study found an association between bedwetting (particularly the severely delayed and persistent bedwetting group) and maternal self-reported anxiety and depressive symptoms experienced when the child was around 21 months old. These findings are supported by evidence from an early clinical study reporting that bedwetting is associated with an increased rate of psychiatric disorder in the mother (Hallgren, 1957). Mothers with depression and/or anxiety are more likely to be hostile and irritable toward their child, to engage in harsh disciplining behaviours, and to be less sensitive or responsive to their child's needs (Sohr-Preston \& Scaramella, 2006; McLearn, Minkovitz, Strobino, Marks, \& Hou, 2006; Nicol-Harper, Harvey \& Stein, 2007). It is possible that these factors could lead to an increased risk of stress or anxiety in the child. This argument is supported by evidence that children's stress hormone levels are influenced by exposure to maternal depression (Ashman, Dawson, 
Panagiotides, Yamada, \& Wilkinson, 2002). According to Jarvelin et al. (1990), at around two years children begin to acquire bladder continence and early stress can interfere with this process. Stress is believed to interfere with the acquisition of bladder co-ordination, leading to bladder over-activity, avoidance of waking to a full bladder, or inhibition of antidiuretic hormone (Houts, 1991). Antidiuretic hormone decreases the amount of urine produced at night, but it also has a role in modulating the response of the hypothalamic-pituitary-adrenal (HPA) axis to stress. The stress hormone cortisol exerts a negative feedback directly on the pituitary and also on the synthesis and secretion of antidiuretic hormone, a lack of which is associated with bedwetting due to the production of more urine than the bladder can hold (Aikawa, Kasahara, Uchiyama, 1998; Rittig et al. 1989).

Exposure to earlier maternal depression and anxiety was also associated with an increased risk of relapse in bedwetting among school age children, again suggesting that primary and secondary enuresis may share a common underlying aetiological basis. However, for the maternal depression/anxiety measures, the pattern of odds ratios for the relapse group in comparison to the other trajectory groups is noticeably different to that found for developmental delay and temperament. In the analysis with developmental delay and temperament, the odds ratios for the relapse group are generally smaller, or similar in magnitude to, the odds ratios for the other groups. In contrast, the adjusted odds ratios for the relapse group are the highest for two of the maternal measures - the anxiety and somatic scales of the CCEI. The stressful effects on the child of exposure to maternal anxiety or somatic symptoms during the sensitive period of learning bladder control could have led to incomplete acquisition of bladder control and increased susceptibility to bedwetting, especially during times of increased stress. It is also possible that mothers reporting experiencing these symptoms when their child was around two years old may have experienced similar symptoms during the assessment period (when their child was 4 to 9 years old) and a relapse in bedwetting at school age could also be related to the effects of proximal exposure to maternal distress and associated life events/stressors.

\section{Limitations}

A small proportion of children had still not attained nighttime bladder control by the end of the assessment period in the current study. Consequently, the prevalence of the group with persistent bedwetting was higher in the current cohort compared to the NSHD cohort, because the time span covered by the parent reports was shorter. If observed until 15 years, then the current study would have had the same time period as in the NSHD for their symptoms to remit and, through a refinement of the trajectory groups, many of the persistent cases may become more similar to the severely delayed group. As a result, we are unable to say whether the trend for an increased association of the contributing factors with increased level of bedwetting (from delayed, to severely delayed to persistent) is actually being driven by children who would be re-classified as severely delayed if the assessment period were to be extended beyond 9 years, rather than those who would remain in the persistent bedwetting group.

In the present study, frequency of bedwetting was not incorporated into the model, but instead bedwetting was treated as a binary outcome variable. This was done to simplify analysis, establish a correspondence with the NSHD analysis and data, and to facilitate graphical presentation of the results. Although we considered using the full ordinal variation in the data captured by the 6-point 'frequency of bedwetting' response scale there is elegance and simplicity in our wet versus dry outcome. In addition, an aim of this study was to show the different developmental trajectories of nighttime bladder control in a non-clinical population and not to focus on children whose bedwetting meets DSM-IV criteria. Since we used a low threshold for bedwetting (i.e. the bedwetting groups were not restricted to children who met DSM-IV criteria), the effect sizes found in this study are relatively small, but they apply to the whole range of bedwetting problems in a sample drawn from the general population. Previous studies on the ALSPAC population have shown that it is important to consider not only those children whose bedwetting meets DSM-IV criteria, but also those with less frequent bedwetting due to a number of adverse psychological outcomes in this group (Joinson et al. 2007b). Another study reported evidence for neurological impairments in children whose bedwetting did not meet DSM-IV criteria (Jarvelin et al. 1991).

It is notable that we found a strong relationship between the trajectory groups and the frequency of bedwetting, with the rates of bedwetting twice or more per week being much higher within the persistent wetting group and very low in the relapsing group. It has been suggested that persistence of 
bedwetting into adolescence and beyond is more likely in children who wet the bed more than twice a week rather than those wetting less frequently (Butler \& Heron, 2008; Yeung, Sreedhar, Silhoe, Sit \& Lau 2006). Future studies with the ALSPAC data are planned, not only extending the trajectories of nighttime bladder control into adolescence, but also incorporating frequency of bedwetting into the longitudinal mixture model. This may help to shed light on whether children who experience frequent bedwetting that persists into late childhood and adolescence may not simply be at the end of a continuum of severity, but may represent a qualitatively distinct group with a different set of contributing factors.

Another possible limitation of this study is that it relied on maternal reports for both bedwetting and the contributing factors relating to the child and mother, thus introducing method bias as a potential explanation for the effects reported in this study. However, we do not feel that method variance is a satisfactory explanation for the effects found in this prospective data because it is highly unlikely that mothers would have invented subsequent bedwetting episodes in their children. Relying on parental reports of children's bedwetting would be potentially more of a problem if the study had examined frequency of wetting, due to the possibility that this could be under/over-estimated by parents. The use of a binary measure of bedwetting should have minimized this limitation as it is unlikely that a child's bedwetting would go entirely unnoticed by parents. It is also possible that parents of children who wet the bed may overestimate problems relating to their child, such as difficult temperament. However, the prospective design of this study means that parental reports of child temperament pre-date the reports of bedwetting problems. Mothers suffering from depression are more likely to view their child negatively (Fergusson, Lynskey \& Horwood, 1993) and this is potentially more of a problem, because maternal depression (assessed when the child was 21 months) may have negatively influenced maternal reports of child temperament (assessed at 24 months).

The methods used have enabled us to dramatically simplify the complex set of responses relating to the occurrence of bedwetting observed within this cohort. We have represented the changing patterns relating to the development of nighttime bladder control of over 10,000 children as four groups with some level of communality in their progression towards continence and have then examined differences in the aetiology of these groups. This modelling approach to describing population heterogeneity is simple to understand and offers a good account of these data. A potential power of group based trajectory modelling over other methods is that it permits the statistical modelling of unobserved heterogeneity in the development of nighttime bladder control and may result in the identification of other groups not predicted by theoretical classification. Identification and analysis of distinctive developmental trajectories of nighttime bladder control is important because it may help to elucidate different risk factors relating to characteristics of individuals and their environments that account for qualitative differences across individuals in their developmental course. Although the trajectory modelling approach can often describe data very well in terms of groups, that does not imply that these groups actually exist, merely that this representation of the data is useful and appealing, especially from the point of view of prognosis and treatment. There is always scientific value in replication of the subgroups in other datasets where additional scientific scrutiny can be gained through external validation against other criteria, such as clinical diagnosis of nighttime enuresis.

\section{Conclusions}

The current study emphasizes the importance of a developmental approach to bedwetting through the examination of different pathways to the attainment of nighttime bladder control, and has broadly replicated the findings of Croudace et al. (2003). The study also examined the role of early-life contributing factors in the development of nighttime bladder control, and these findings are supported by, and also extend, previous studies of bedwetting. In particular, the association of bedwetting with maturation level has been widely reported, but this is the first study to show that there is a trend for increasing odds of developmental delay with increasing delay of nighttime bladder control. Associations between early temperament and subsequent bedwetting were also examined for the first time in this study. The link with more difficult temperament traits may relate to early indicators of externalizing or internalizing problems, shown by previous studies to be co-morbid with nocturnal enuresis. The current study also adds to the literature on the association between stress and bedwetting, showing that children exposed to maternal depressive and anxiety symptoms at around two years have an increased risk of problems attaining nighttime bladder control. Increased understanding of the contributing factors that lead to problems attaining nighttime bladder control is 
essential because a significant proportion of children suffer from bedwetting into their school years, and if these problems remain unresolved or untreated they can become socially and psychologically debilitating (Butler, 2001; Issenman, Filmer \& Gorski, 1999).

Important areas to consider for future research include, investigating whether the contributing factors identified in the current study anticipate children with increased vulnerability to problems with nighttime bladder control, and whether interventions targeting factors such as exposure to maternal depression, result in a decreased risk of bedwetting. Future studies should extend the age range covered in the current study, to investigate contributing factors associated with bedwetting that persists into adolescence and adulthood. A comprehensive examination of other potential contributing factors, including family history, prenatal influences, toilet training practices and life events, is also needed in order to shed light on the aetiology of this prevalent childhood problem.

\section{Acknowledgements}

This study is based on the Avon Longitudinal Study of Parents and Children (ALSPAC). We are extremely grateful to all the families who took part in this study, the midwives for their help in recruiting them, and the whole ALSPAC team, which includes interviewers, computer and laboratory technicians, clerical workers, research scientists, volunteers, managers, receptionists and nurses. The UK Medical Research Council, the Wellcome Trust and the University of Bristol provide core support for ALSPAC. This publication is the work of the authors who also serve as guarantors for the contents of this paper. This research was specifically funded by a grant from the Big Lottery Fund (title: The causes and consequences of childhood wetting and soiling: clues to improving the social \& educational experiences for children with bladder \& bowel difficulties; reference: ERIC BS15 8DB) and has been carried out in collaboration with the charity ERIC (Education and Resources for Improving Childhood Continence).

\section{References}

Aikawa T, Kasahara T, Uchiyama M. (1998) The arginine-vasopressin section profile of children with primary nighttime enuresis. European Urology, 33(3), 41-44.

Ashman SB, Dawson G, Panagiotides H, Yamada E, Wilkinson CW. (2002) Stress hormone levels of children of depressed mothers. Developmental Psychopathology, 14(2), 333-349.

Barbour AF, Boyd MM, Borland EM, Miller S, Oppel TE. (1963) Enuresis as a disorder of development. British Medical Journal, 28, 787-790.

Baeyens D, Roeyers H, Van Erdeghem S, Hoebeke P, Vande Walle J. (2007) The prevalence of attention deficit-hyperactivity disorder in children with nonmonosymptomatic nocturnal enuresis: a 4-year followup study. Journal of Urology, 178(6):2616-20. Epub 2007 Oct 22.

Blomfield JM, Douglas, JW. (1956) Bedwetting; prevalence among children aged 4-7 years. Lancet, 270(6927), 850-852.

Blum NJ, Taubman B, Nemeth N. (2004) Why is toilet training occurring at older ages? A study of factors associated with later training. Journal of Pediatrics, 145(1), 107-111.

Butler RJ. (2001). Impact of nocturnal enuresis on children and young people. Scandinavian Journal of Urology and Nephrology, 35, 169-176.

Butler RJ, Golding J, Northstone K. (2005) Nighttime enuresis at 7.5 years old: prevalence and analysis of clinical signs. British Journal of Urology International, 96(3), 404-410.

Butler RJ, Heron J. (2008) The prevalence of infrequent bedwetting and nighttime enuresis in childhood: a large British cohort. Scandinavian Journal of Urology and Nephrology, 42(3), 257-64. 
Butler RJ, Redfern E J, Forsyth I. (1993) The Maternal Tolerance Scale and nighttime enuresis. Behaviour Research and Therapy, 31(4), 433-6.

Byrd RS, Weitzman M, Lanphear NE, Auinger P. (1996) Bed-wetting in US children: epidemiology and related behaviour problems. Pediatrics, 98(3 Pt 1), 414-419.

Cicchetti D, Rogosch FA, Toth SL. (1998) Maternal depressive disorder and contextual risk: contributions to the development of attachment insecurity and behaviour problems in toddlerhood. Developmental Psychopathology, 10(2), 283-300.

Cox JL, Holden JM, Sagovsky R. (1987) Detection of postnatal depression. Development of the 10-item Edinburgh Postnatal Depression Scale. British Journal of Psychiatry, 150, 782-786.

Croudace TJ, Jarvelin MR, Wadsworth ME, Jones PB. (2003) Developmental typology of trajectories to nighttime bladder control: epidemiologic application of longitudinal latent class analysis. American Journal of Epidemiology, 157(9), 834-842.

Crown S, Crisp, AH. (1979). Manual of the Crown-Crisp Experiential Index. London: Hodder and Stoughton.

Crown S, Duncan KP, Howell RW. (1970) Further Evaluation of the Middlesex Hospital Questionnaire (M.H.Q.). British Journal of Psychiatry, 116, 33-37.

Douglas JWB. (1973) Early disturbing events and later enuresis. In I. Colvin, R. C. MacKeith, \& S. R. Meadow (Eds.), Bladder control and enuresis. Pp109-117. London: Heinemann.

Downey G, Coyne JC. (1990) Children of depressed parents: an integrative review. Psychological Bulletin, 108(1), 50-76.

Essen J, Peckham C. (1976) Nighttime enuresis in childhood. Developmental Medicine and Child Neurology, 18(5), 577-589.

Evans J, Heron J, Francomb H, Oke S, Golding J and the ALSPAC Study Team. (2001) Cohort study of depressed mood during pregnancy and after childbirth. British Medical Journal, 323:257-260.

Fergusson DM, Horwood LJ, Shannon FT. (1986) Factors related to the age of attainment of nighttime bladder control: an 8-year longitudinal study. Pediatrics, 78(5), 884-890.

Fergusson DM, Horwood LJ, Shannon FT. (1990) Secondary enuresis in a birth cohort of New Zealand children. Paediatric and Perinatal Epidemiology, 4, 53-63.

Fergusson DM, Lynskey MT, Horwood LJ. (1993) The effect of maternal depression on maternal ratings of child behavior. Journal of Abnormal Child Psychology. 21(3), 245-69.

Frankenburg WK, Dodds J, Archer P, Shapiro H, Bresnick B. (1992) The Denver II: a major revision and restandardization of the Denver Developmental Screening Test. Pediatrics, 89(1), 91-97.

Fullard W, McDevitt SC, Carey WB. (1984) Assessing temperament in one- to three-year-old children. Journal of Pediatric Psychology, 9(2), 205-217.

Golding J, Pembrey M, Jones R. (2001) ALSPAC--the Avon Longitudinal Study of Parents and Children. I. Study methodology. Paediatric and Perinatal Epidemiology, 15(1), 74-87.

Hallgren B. (1957) Enuresis: A Clinical and Genetic Study. Acta Psychiatrica Scandinavica, 32 (Suppl. 114): 1-159.

Heron J, Joinson C, Croudace,T, von Gontard A (2008) Trajectories of daytime wetting and soiling in a UK population of 4 to 9 year olds. Journal of Urology, 179(5),1970-5. 
Houts AC. (1991) Nighttime enuresis as a bio-behavioural problem. Behaviour Therapy 22, 133-151.

Issenman RM, Filmer RB, Gorski PA. (1999) A review of bowel and bladder control development in children: how gastrointestinal and urologic conditions relate to problems in toilet training. Pediatrics, 103(6 Pt 2), 1346-1352.

Jarvelin MR. (1989) Developmental history and neurological findings in enuretic children. Developmental Medicine and Child Neurology, 31(6), 728-736.

Jarvelin MR, Moilanen I, Kangas P, Moring K, Vikevainen-Tervonen L, Huttunen NP, et al. (1991) Aetiological and precipitating factors for childhood enuresis. Acta Psychiatrica Scandinavica, 80(3), 361-369.

Jarvelin MR, Moilanen I, Vikevainen-Tervonen L, \& Huttunen NP. (1990) Life changes and protective capacities in enuretic and non-enuretic children. Journal of Child Psychology and Psychiatry, 31(5), 763-774.

Joinson C, Heron J, Butler R, von Gontard A, Butler U, Emond A, Golding J.(2007)a A United Kingdom population-based study of intellectual capacities in children with and without soiling, daytime wetting, and bed-wetting. Pediatrics, 120(2), e308-16.

Joinson C, Heron J, Emond A, Butler R. (2007)b Psychological problems in children with bedwetting and combined (day and night) wetting: A UK population-based study. Journal of Pediatric Psychology, 32(5), 605-616.

Joinson C, Heron J, von Gontard A, Butler U, Golding J, Emond, A. (2008) Early Childhood Risk Factors Associated with Daytime Wetting and Soiling in School-age Children. Journal of Pediatric Psychology, 33(7), 739-50.

Kaffman M, Elizur E. (1977) Infants who become enuretics: a longitudinal study of 161 kibbutz children. Monographs of the Society for Research in Child Development, 42(2), 1-61.

Kawauchi A, Tanaka Y, Yamao Y, Inaba M, Kanazawa M, Ukimura O, Mizutani Y, Miki T. (2001) Follow-up study of bedwetting from 3 to 5 years of age. Pediatric Urology, 58(5), 772-6.

Koff S. (1996) Cure of nocturnal enuresis: why isn't desmopression very effective? Pediatric Nephrology, 10(667-670).

Kolvin I, Taunch J. (1973) A dual theory of nighttime enuresis. In I. Colvin, R. C. MacKeith, \& S. R. Meadow (Eds.). Bladder control and enuresis. Pp. 156-172. London: Heinemann.

Largo RH, Molinari L, von Siebenthal K, Wolfensberger U. (1999) Development of bladder and bowel control: significance of prematurity, perinatal risk factors, psychomotor development and gender. European Journal of Pediatrics, 158(2), 115-122.

McLearn KT, Minkovitz CS, Strobino DM, Marks E, Hou W. (2006) The timing of maternal depressive symptoms and mothers' parenting practices with young children: implications for pediatric practice. Pediatrics, 118(1), e174-82.

MacKeith RC. (1968) A frequent factor in origins of primary nighttime enuresis: anxiety in the third year of life. Developmental Medicine and Child Neurology, 10, 465-470.

Moilanen I, Järvelin MR, Vikevaeinen-Tervonen L, Hunttunen NP. (1987). Personality and family characteristics of enuretic children. Psychiatrica Fennica, 18, 53-61.

Muris P, Ollendick TH. (2005) The role of temperament in the etiology of child psychopathology. Clin Child Fam Psychol Rev, 8(4), 271-89. 
Muthén LK, Muthén BO. Mplus User's Guide, Fourth Edition (1998-2006) Los Angeles, CA: Muthén \& Muthén. Muris P, Ollendick TH. (2005) The role of temperament in the etiology of child psychopathology. Clinical Child and Family Psychology Review, 8(4), 271-89.

Nagin DS, Tremblay R. (2005) What has been learned from group-based trajectory modelling? Examples from physical aggression and other problem behaviours. Annals of the American Academy of Political and Social Science, 602, 82-117.

Nicol-Harper R, Harvey AG, Stein A. (2007) Interactions between mothers and infants: impact of maternal anxiety. Infant Behavior and Development, 30(1), 161-7. Epub 2006 Sep 12.

Nylund KL, Asparouhov T, Muthen BO. (2007) Deciding on the Number of Classes in Latent Class Analysis and Growth Mixture Modelling: A Monte Carlo Simulation Study. Structural Equation Modelling: A Multidisciplinary Journal, 14, (4), 535-569.

Oldehinkel AJ, Hartman CA, De Winter AF, Veenstra R, Ormel J. (2004) Temperament profiles associated with internalizing and externalizing problems in preadolescence. Developmental Psychopathology, $16(2), 421-40$.

Oppel WC, Harper PA, Rider RV. (1968) The age of attaining bladder control. Pediatrics, 42(4), 614-626.

Ornitz EM, Russell AT, Hanna GL, et al. (1999) Prepulse inhibition of startle and the neurobiology of primary nocturnal enuresis. Biological Psychiatry, 45(11), 1455-66.

Ramaswamy V, DeSabro W, Reibstein D, Robinson W. (1993) An empirical pooling approach for estimating marketing mix elasticities with PIMS data. Marketing Science, 12, 103-124.

Rittig S, Knudsen UB, Norgaard JP, Pedersen EB, Djurhuus JC. (1989) Abnormal diurnal rhythm of plasma vasopressin and urinary output in patients with enuresis. American Journal of Physiology, 256(4 Pt 2), F664-671.

Ross LE, McLean LM. (2006) Anxiety disorders during pregnancy and the postpartum period: A systematic review. Journal of Clinical Psychiatry, 67(8), 1285-1298.

Rutter M. (1989) Psychiatric disorder in parents as a risk factor for children. In Schaffer D, Phillips I, Enger NB, eds. Prevention of mental disorder, alcohol and other drug use in children and adolescents. Rockville, Maryland: Office for Substance Abuse, USDHHS, 1989.

Schonwald A, Sherritt L, Stadtler A, Bridgemohan, C (2004) Factors associated with difficult toilet training. Pediatrics, 113(6), 1753-1757.

Schwarz G. (1978) Estimating the dimension of a model. Annals of Statistics, 6, 461-464.

Sohr-Preston, SL, Scaramella LV. (2006) Implications of timing of maternal depressive symptoms for early cognitive and language development. Clinical Child and Family Psychology Review, 9(1), 65-83.

Srivastava AK, Nigam A, Sing SB. (1982). The personality characteristics of enuretic children. Child Psychiatry Quarterly, 15, 109-112.

Stein Z, Susser M. (1967) Social factors in the development of sphincter control. Developmental Medicine and Child Neurology, 9(6), 692-706.

Touchette E, Petit D, Paquet J, Tremblay RE, Boivin M, Montplaisir JY. (2005) Bed-wetting and its association with developmental milestones in early childhood. Archives of Pediatric Adolescent Medicine, 159(12), 1129-1134.

von Gontard A, Freitag CM, Seifen S, Pukrop R, Rohling D. (2006) Neuromotor development in nighttime enuresis. Developmental Medicine and Child Neurology, 48(9), 744-750. 
von Gontard A, Hollmann E. (2004) Co-morbidity of functional urinary incontinence and encopresis: somatic and behavioural associations. Journal of Urology, 171(6 Pt 2), 2644-2647.

von Gontard A, Schmelzer D, Seifen S, Pukrop R. (2001) Central nervous system involvement in nighttime enuresis: evidence of general neuromotor delay and specific brainstem dysfunction. Journal of Urology, 166(6), 2448-2451.

Wechsler D, Golombok S, Rust J. (1992) WISC-III UK: Wechs/er Intelligence Scale for Children - Third Edition UK Manual. Sidcup, UK: The Psychological Corporation.

Werry JS. (1967) Enuresis-a psychosomatic entity? Can Med Assoc J, 97(7), 319-327.

Wolfish NM, Pivik RT, Busby KA. (1997) Elevated sleep arousal thresholds in enuretic boys: clinical implications. Acta Paediatrica, 86(4), 381-4.

Yeung CK, Sreedhar B, Sihoe JD, Sit FK, Lau J. (2006) Differences in characteristics of nighttime enuresis between children and adolescents: a critical appraisal from a large epidemiological study. British Journal of Urology International, 97(5), 1069-1073. 
